\title{
Common patterns, common drivers: comparative analysis of aggregate surplus production across ecosystems
}

\author{
Alida Bundy ${ }^{1, *}$, Erin C. Bohaboy ${ }^{2,7}$, Dag O. Hjermann ${ }^{3}$, Franz J. Mueter ${ }^{4}$, \\ Caihong Fu' ${ }^{5}$, Jason S. Link \\ ${ }^{1}$ Bedford Institute of Oceanography, Dartmouth, Nova Scotia B2Y 4A2, Canada \\ ${ }^{2}$ Graduate School of Oceanography, University of Rhode Island, Narragansett, Rhode Island 02882, USA \\ ${ }^{3}$ Department of Biology, Center of Ecological and Evolutionary Synthesis, University of Oslo, 0316 Oslo, Norway \\ ${ }^{4}$ Fisheries Division, School of Fisheries and Ocean Sciences, University of Alaska Fairbanks, Juneau, Alaska 99801, USA \\ ${ }^{5}$ Pacific Biological Station, Marine Ecosystems and Aquaculture Division, Fisheries \& Oceans Canada, Nanaimo, \\ British Columbia V9T 6N7, Canada \\ ${ }^{6}$ National Atmospheric and Oceanic Administration, National Marine Fisheries Service, Northeast Fisheries Science Center, \\ Woods Hole, Massachusetts 02543, USA \\ ${ }^{7}$ Present address: RPS ASA, South Kingstown, Rhode Island 02879, USA
}

\begin{abstract}
Marine ecosystems are dynamic, often have open boundaries, and their overall productivity responds nonlinearly to multiple drivers acting at multiple temporal and spatial scales, under a triad of influences: climatic, anthropogenic, and ecological. In order to further our understanding of how the structure and functioning of marine ecosystems influence and regulate patterns of fisheries production, and how they are affected by this triad of drivers, a comparative approach is required. We apply a system-level surplus production modeling approach to the total aggregated catch and biomass of all major targeted fish species in 12 exploited Northern Hemisphere ecosystems. We use 2 variations of a surplus production model: a regression model and a dynamic model, each fit with and without environmental and biological covariates. Our aims were to explore (1) the effects of common drivers at the basin scale and their relative influence within the triad of drivers among systems, (2) the impact of covariates on biological reference points and implications for fisheries management, and (3) the relationship between maximum sustainable yield (MSY) and production. Our results show that the environment affects estimates of systemlevel MSY across all ecosystems studied and that specifically water temperature is a major influence on productivity. Emergent properties of northern hemisphere systems suggest that MSY values and optimal exploitation rates are relatively consistent: MSY ranges between 1 and $5 \mathrm{t} \mathrm{km}^{-2}$ and optimal exploitation rate between 0.1 and $0.4 \mathrm{yr}^{-1}$. Finally, we suggest that the relationship between fisheries yield and primary production is not as simple as suggested in other studies. These results put fisheries in a broader ecosystem context and have implications for an ecosystem approach to management.
\end{abstract}

KEY WORDS: Multiple ecosystem drivers · Surplus production models · Comparative analysis Resale or republication not permitted without written consent of the publisher

\section{INTRODUCTION}

Living marine resources inhabit a complex world, influenced by multiple physical, environmental, an- thropogenic, and biotic drivers that operate and interact over multiple scales (deYoung et al. 2004) that can result in nonlinear or abrupt responses to perturbation (e.g. Hare \& Mantua 2000, Hunt et al. 
2002, Scheffer \& Carpenter 2003, Steele 2004). Trophodynamically, marine food webs are dynamic, often have open boundaries, and respond nonlinearly to climatic, anthropogenic, and ecological influences (Hsieh et al. 2005). Until relatively recently, management of living marine resources largely ignored this complexity, focusing on single-species stock assessment. This is one of the many contributing factors to the series of fisheries crises (stock collapses and fisheries closures) witnessed over the last 2 decades (e.g. Smith 1994, Mullon et al. 2005, Smith \& Link 2005, Murawski 2007, Branch et al. 2011, Pinsky et al. 2011). While the solution and the way forward towards successful resource management does not rest in science alone (Frid et al. 2006, Bundy et al. 2008, Fulton et al. 2011), robust science advice, grounded in an ecosystem context, is an essential component. The inherent complexity and the large scale of marine ecosystems suggests that progress toward an understanding of how the structure and functioning of marine ecosystems influence and regulate patterns of fisheries production will be most effective if researchers adopt a comparative approach (Link et al. 2010a, Murawski et al. 2010), since this is similar to the replication method traditionally used in experimental science. This approach has been amply demonstrated in empirical studies (e.g. Bundy et al. 2009, 2010, Gaichas et al. 2009, Link et al. 2009, 2010b, Shackell et al. 2012). However, there is an additional need to explore mechanistic understandings and drivers of ecosystem structure, functioning, and production as revealed by such comparisons.

Mechanistic approaches vary from the simple to the complex. However, comparative analyses require standardized methods that can be applied across multiple ecosystems and that produce standardized results for comparison. Complex methods are usually developed or tailored for a specific system and are time-consuming to parameterize and fit. Hence such models are challenging to use in a comparative approach since they require far more time, resources, and co-ordination. Rather, comparative approaches, especially over a broad range of ecosystems, are most readily addressed using simpler methods such as production models (Walters \& Hilborn 1976, Jacobson et al. 2001, Mueter \& Megrey 2006, Gaichas et al. 2012a, this Theme Section). These models relate the production of a population to current population size, given an intrinsic rate of productivity and a finite carrying capacity to account for density-dependent effects. As for all models, they are reductionist representations of complex processes, and though there has been some debate about their utility in specific applications (Mohn 1980, Ludwig \& Walters 1985, 1989, Punt 2003), there is consensus that they play a useful and important role in ecology in general (Mangel 2006) and fisheries science in particular (Ludwig \& Walters 1985, 1989, NRC 1998).

Production models are a useful method to compare fish communities across ecosystems and drivers because: (1) data requirements are relatively simple and data are readily available, (2) they are robust to various assumptions (Ludwig \& Walters 1989), (3) they can sometimes outperform more complicated (i.e. stage or age-structured) fisheries models (Ludwig \& Walters 1985, 1989, Hilborn \& Walters 1992), (4) they produce standard outputs that are readily comparable, (5) they can be scaled to different spatial and organizational levels, and (6) they can incorporate drivers as covariates (Jacobson et al. 2005, Mueter \& Megrey 2006). In addition, the outputs of these models can be readily related to commonly used fishery management biological reference points (BRPs) such as maximum sustainable yield (MSY) and the biomass $\left(B_{\mathrm{MSY}}\right)$ or fishing mortality rate ( $\left.F_{\mathrm{MSY}}\right)$ corresponding to MSY (Restrepo et al. 1999, Mueter \& Megrey 2006).

Here we use surplus production modeling to compare the influence of a triad of drivers (fishery exploitation, trophic interactions, and environmental drivers) on fishery production. We apply 2 systemlevel surplus production models (regression and dynamic) to the total aggregated biomass of all targeted fish species in 12 exploited northern hemisphere ecosystems. We do so with and without environmental and biological covariates to explore the effects of selected drivers on production.

We take an aggregate, system-level approach (e.g. Mueter \& Megrey 2006) for the following reasons. (1) Fundamentally, the energy available to all fish and invertebrates originates from lower trophic levels and is limited and shared by the entire marine community (Pauly \& Christensen 1995, Pauly et al. 1998, 2002). Lower-trophic-level production has been shown to limit fisheries production (Iverson 1990, Ware \& Thomson 2005, Chassot et al. 2007, 2010). These analyses suggest that the production potential for marine resources in any given area of the ocean is, within ranges of natural variation, relatively fixed due to lower-trophic-level production. (2) Due to species interactions, and differences in productivity among fish stocks, the aggregate management objective is not the simple sum of the single-stock objectives (e.g. Brown et al. 1976, Walters et al. 2005, Mueter \& Megrey 2006, Tyrrell et al. 2011). There- 
fore an average or aggregate quota may sometimes be more appropriate, especially when managing suites of stocks (May 1975, Pope 1975, 1979, Fukuda 1976, Mayo et al. 1992), and provides additional precaution (in addition to stock-specific quotas) when used to constrain total removals from a system (Witherell et al. 2000, Mueter \& Megrey 2006). (3) Aggregate surplus production models often fit better than production models applied on a species-by-species basis (FAO 1978, Ralston \& Polovina 1982).

Comparing responses in aggregate production across multiple ecosystems elucidates both common, generic patterns and those processes that are unique to particular ecosystems. Our aims are to use total, system-level estimates of BRPs based on production models to explore (1) the effects of common drivers at the basin scale and their relative influence within the triad of drivers among systems, (2) the impact of covariates on BRPs and implications for fisheries management, and (3) the relationship between MSY and production.

\section{METHODS}

\section{Data}

Biomass, landings, and relevant environmental data were compiled for 12 temperate and sub-arctic marine ecosystems in the northern hemisphere (Table 1) (see Fu et al. 2012, this Theme Section, for further descriptions). The principal marine species were selected for each ecosystem based on prevalence in the landings and biomass data as well as importance in the marine community. These species together comprise a large majority of total trawlable fish biomass in each system. We used biomass estimates from stock assessments when available and survey-based estimates otherwise. Stock assessment estimates of biomass typically corresponded to the exploitable portion of total biomass, assuming knife-edge recruitment. Swept-area estimates of survey biomass were expanded to the total area of the ecosystem and were corrected for catchability when possible. Biomass was summed by year over all selected species to obtain time series of aggregated biomass for each ecosystem. Similarly, reported landings were summed by year over all se- lected species to obtain time series of aggregate landings for each ecosystem. The landings represent the majority, if not all, recorded catch, but do not account for non-recorded by-catch or discards. Principal species, years, data types, and sources of biomass and landings data for each system are detailed in Table $\mathrm{S} 1$ in the supplement at www.int-res.com/ articles/suppl/m459p203_supp.pdf.

Environmental and biological covariates for each system were selected by regional experts who were asked to identify those regional and basin-scale variables that are generally considered to be important drivers of productivity in a given ecosystem. Available time series data were compiled for each system that included water temperature, stratification, largescale climatic indices, freshwater discharge, and abundances of important top-level predators (Table $\mathrm{S} 2$ in the supplement). All covariates were standardized to have mean $=0$ and standard deviation $(\mathrm{SD})=$ 1 over the time series.

\section{Models}

The productivity of each of the 12 ecosystems and the influence of environmental covariates on productivity were compared using a surplus production modeling approach. Since we don't know the true dynamics of these systems, we used 2 different approaches to examine surplus production dynamics: a regression approach that models empirical estimates of annual surplus production as a quadratic function of biomass (Graham-Schaefer functional form with additive errors); and a dynamic surplus production model of the Graham-Schaefer form with multiplicative errors.

Table 1. Marine ecosystems in the present study. 'Species' means principal marine species (see Table S1 in the supplement at www.int-res.com/articles/ suppl/m459p203_supp.pdf)

\begin{tabular}{|lccc|}
\hline System & Abbreviation & Area $\left(\mathrm{km}^{2}\right)$ & No. of species \\
\hline Eastern Bering Sea & EBS & 430829 & 8 \\
Gulf of Alaska & GOA & 238439 & 13 \\
Hecate Strait & HS & 23501 & 20 \\
Georges Bank & GB & 42154 & 18 \\
Gulf of Maine & GOM & 76483 & 19 \\
Western Scotian Shelf & WSS & 73344 & 23 \\
Eastern Scotian Shelf & ESS & 113704 & 24 \\
Newfoundland/Labrador & NL & 388204 & 13 \\
Southern Gulf & GOSL & 74137 & 20 \\
of St. Lawrence & NS & 728331 & 3 \\
Norwegian Sea & BS & 747893 & 8 \\
Barents Sea & Nort & 609748 & 9 \\
North Sea & & & \\
\hline
\end{tabular}




\section{Regression models}

The observed annual surplus production in year $t$ $\left(\mathrm{ASP}_{t}\right)$ was calculated as:

$$
\mathrm{ASP}_{t}=B_{t+1}-B_{t}+C_{t}
$$

where $B_{t}$ is the biomass summed across all ages in year $t_{1} B_{t+1}$ is the following year's biomass, and $C_{t}$ is the catch in year $t$. The Graham-Schaefer model describes $\mathrm{ASP}_{t}$ as a quadratic function of $B_{t}$ and a linear function of a covariate as:

$$
\mathrm{ASP}_{t}=\alpha B_{t}+\beta B_{t}^{2}+\delta X_{t-1}+\varepsilon_{t}
$$

where $\alpha, \beta$, and $\delta$ are regression parameters, $X_{t-1}$ is an environmental or biological covariate measured in year $t-1$, normalized to mean 0 with $\mathrm{SD}=1$ (Table S2 in the supplement), and $l$ represents the time lag (in years, ranging from $l=0$ to $l=7$ ) before effects on ASP are realized. Parameter $\delta$ represents the magnitude and sign of the effect of the biological or environmental covariate on $\mathrm{ASP}_{t}$ and can be directly compared across different standardized covariates. If residuals from the model $\left(\varepsilon_{t}\right)$ had significant autocorrelation (Durbin-Watson test, $\mathrm{p}<0.10$ ), the model was refit under the assumption that residuals follow a first-order autoregressive process:

$$
\varepsilon_{t}=\varphi \cdot \varepsilon_{t-l}+v_{t}
$$

with coefficient $\varphi$ and independent, normally distributed annual deviations $\left(v_{t}\right)$ with mean $=0$ and variance $=\sigma_{v}^{2}$ :

$$
v_{t} \sim N\left(0, \sigma_{v}^{2}\right)
$$

All parameters were estimated using a generalized least-squares regression approach as implemented in the 'nlme' package (Pinheiro \& Bates 2000) in R (R Development Core Team 2011). Maximum surplus production was taken to represent MSY and was calculated as follows (for models with covariates, MSY corresponds to average environmental conditions):

$$
\text { MSY }=-\alpha^{2} / 4 \beta
$$

We also calculated the biomass at which MSY occurs $\left(B_{\mathrm{MSY}}\right)$ and defined the optimal exploitation rate $F_{\text {MSY }}^{\prime}$ as the ratio MSY/ $B_{\mathrm{MSY}}$. (Note that $F_{\text {MSY }}^{\prime}$ expresses an exploitation rate, i.e. landings as a fraction of the total biomass, rather than the instantaneous fishing mortality, as is the common usage of $F_{\mathrm{MSY}}$.) The potential effects of covariates on ASP were estimated separately for each covariate and at each of multiple lags, and the resulting coefficients, $t$-statistics, and p-values were summarized and examined.

\section{Biomass dynamic models}

Following Walters \& Hilborn (1976), the predicted biomass in year $t+1\left(\hat{B}_{\mathrm{t}+1}\right)$ was calculated as

$$
\hat{B}_{t+1}=\hat{B}_{t}+r_{t} \hat{B}_{t}\left(1-\frac{\hat{B}_{t}}{k}\right)-C_{t}+\varepsilon_{t}
$$

where $\hat{B}_{t}$ is the predicted biomass in year $t$, and $C_{t}$ is the observed catch in year $t$. The intrinsic population growth rate in year $t\left(r_{t}\right)$ and the equilibrium population size in the absence of catch $(k$, also referred to as the carrying capacity) are parameterized quantities. The initial biomass $\left(B_{t=0}\right.$ or $\left.B_{0}\right)$ is also an estimated parameter.

For any year $t, r_{t}$ can be expressed as a function of an environmental or biological covariate in year $t$ $\left(X_{t-1}\right)$, where 1 represents a time lag (in number of years, ranging from $l=0$ to $l=7$ ) before effects on $r$ are realized (Mueter \& Megrey 2006):

$$
r_{t}=r_{m} \mathrm{e}^{\gamma X_{t-1}}
$$

Covariates were standardized to have mean $=0$ and $\mathrm{SD}=1$ over the time series; hence the expected value of $r_{t}$ under average environmental conditions $\left(X_{t-1}=0\right)$ is $r_{m}$. Parameter $\gamma$ represents the magnitude and sign of the effect of the biological or environmental covariate on $r_{t}$ and can directly be compared across different standardized covariates.

The model residuals $\left(\varepsilon_{t}\right)$ are assumed to follow a log-normal distribution with mean $=0$ and variance $=$ $\sigma_{v}^{2}$, i.e.:

$$
\varepsilon \sim \ln N\left(0, \sigma_{v}^{2}\right)
$$

The model was implemented in AD Model Builder, a $\mathrm{C}++$ software language extension and automatic differentiation library (ADMB Project 2009), and all parameters were estimated by maximizing the likelihood. MSY and $B_{\mathrm{MSY}}$ were calculated as

$$
\begin{aligned}
\text { and } \quad \mathrm{MSY} & =\frac{r_{m} k}{4} \\
B_{\mathrm{MSY}} & =\mathrm{k} / 2
\end{aligned}
$$

When comparable, the relative value of each model (e.g. with versus without a particular environmental covariate) was evaluated using the small sample Akaike information criterion $\mathrm{AIC}\left(\mathrm{AIC}_{\mathrm{c}}\right.$ ) Hurvich \& Tsai 1989).

$$
\mathrm{AIC}_{\mathrm{C}}=-2 \times \operatorname{LL}(\theta \mid B)+2 K\left(\frac{n}{n-K-1}\right)
$$

where $\operatorname{LL}(\theta \mid B)$ is the loglikelihood of a particular set of parameter values $(\theta)$ given the observed biomass data $(B)$, and $K$ is the number of parameters estimated in the model.

$$
\mathrm{LL}(\theta \mid B)=-\frac{1}{2} n \ln \sum_{t=1}^{n}\left(\ln \hat{B}_{t}-\ln B_{t}\right)^{2}
$$

The number of years of observed biomass is denoted by $n$.

For each modeling approach, we report 2 sets of results: the model fitted without covariates and the model fitted with the covariate giving the largest improvement in model fit. Thus, for each ecosystem we obtain 4 estimates of biological parameters, in- 
cluding MSY, $B_{\mathrm{MSY}}$, and $F_{\mathrm{MSY}}^{\prime}$. For comparing among systems, MSY and $B_{\mathrm{MSY}}$ were standardized to t per $\mathrm{km}^{2}$ by dividing by the area of each system (Table 1 ).

\section{Comparative analysis of ecosystem parameters}

Estimates of MSY, $F_{\mathrm{MSY}}$, and $B_{\mathrm{MSY}}$ were compared across systems and across models - regression and biomass dynamic model (hereafter referred to the dynamic model), each with and without covariates using a weighted least-squares regression (2-way ANOVA) with weights that were inversely proportional to their estimated variances (Jennrich 1995). To investigate how potential fish productivity varies among ecosystems, MSY per unit area was analyzed using simple linear regressions and multiple linear regressions with the following variables as potential explanatory variables: mean chlorophyll a $(\mathrm{chl} a)$ concentration from NASA's SeaWiFS Project (we used the monthly level-3 processed data averaged over each large marine ecosystem [LME] for the period 1998-2009 to compute an annual mean concentration in $\mathrm{mg} \mathrm{m}^{-3}$; http://oceancolor.gsfc.nasa.gov); mean primary production (PP) as estimated from SeaWiFS data (Behrenfeld \& Falkowski 1997); mean mass flux index (a measure of the vertical mass flux of particulate organic carbon [POC]; estimates of normalized annual flux of organic carbon $[\mathrm{FCo}, \mathrm{mmol}$ $\mathrm{m}^{-2} \mathrm{yr}^{-1}$ ] were derived from a model developed from globally observed fluxes [Honjo et al. 2008, Friedland et al. 2012] and remotely sensed chl $a$ and sea surface temperature [SST] [K. Friedland pers. comm.]); mean wind speed (Kalnay et al. 1996); and ecosystem area (Table 1).

\section{RESULTS}

\section{Regression (ASP) models}

There was large variation in biomass among time series (Fig. 1); for the regions with large variation in biomass, there were typically long-term trends such as overall declining (e.g. Hecate Strait) or increasing biomass (e.g. Norwegian Sea), or prolonged periods of both increases and declines (e.g. eastern Scotian Shelf). Similarly, landings data often showed longterm trends (Fig. S1 in the supplement). In contrast, ASP was characterized by high interannual variability rather than long-term trends, even for ecosystems with relatively stable biomass such as the Gulf of Alaska (Fig. 2).
Estimates of maximum production (MSY per unit area), $B_{\mathrm{MSY}}$, and $F_{\mathrm{MSY}}^{\prime}$ varied considerably among regions (Fig. 3; see Table S3 in the supplement for model parameters). The limited contrast in biomass in some regions (Gulf of Alaska, North Sea) resulted in unreliable estimates of $B_{\mathrm{MSY}}$ below the minimum observed biomass, while $B_{\mathrm{MSY}}$ was close to the maximum observed biomass in the Norwegian Sea due to an increasing trend in biomass throughout most of the time series. Neither the regression nor the dynamic model was able to produce credible estimates of MSY for the Gulf of St. Lawrence, likely due to the highly variable input biomass data (Fig. 1), so this system was dropped from further analysis.

Including environmental covariates improved model fits significantly in most systems, with temperature or temperature-related indices resulting in the best model fits in most cases (Table 2; see Table S4 in the supplement for model parameters). One to 3 different covariates significantly improved the fit, according to $\triangle \mathrm{AIC}_{\mathrm{c}}$ (Table 2). Time lags between environmental variables and regression for the bestfit models spanned the range, but most were 4 yr or less. The estimated environmental effects helped capture the trends in the observed ASP series, such as the declining trend in ASP on the eastern Scotian Shelf, multi-year variability off NewfoundlandLabrador and in the Barents Sea, and interannual variability in the Norwegian Sea (Fig. 3).

\section{Biomass dynamic models}

The dynamic Graham-Schaefer model captured the major trends in biomass over time in most systems, but resulted in poor fits in some regions (e.g. Georges Bank, eastern Scotian Shelf, western Scotian Shelf, North Sea; Fig. 4). Including environmental covariates considerably improved the fit of the estimated biomass trajectories in most, but not all systems. The estimated biomass trajectories for the western Scotian Shelf and eastern Scotian Shelf differed substantially between the model with and without environmental covariates, but neither model resulted in a satisfactory fit to the observed time series. Both models (with and without covariates) also failed to capture biomass trends in the North Sea or on Georges Bank. For the Gulf of Alaska and Newfoundland models, although adding environmental covariates did improve the model fit based on the sum of squares (SSQ) (also see Fig. 4), the low value of the $\Delta \mathrm{AIC}_{\mathrm{c}}$ (Table 2) indicates that the addition of this parameter is not justified. Similar to the regres- 

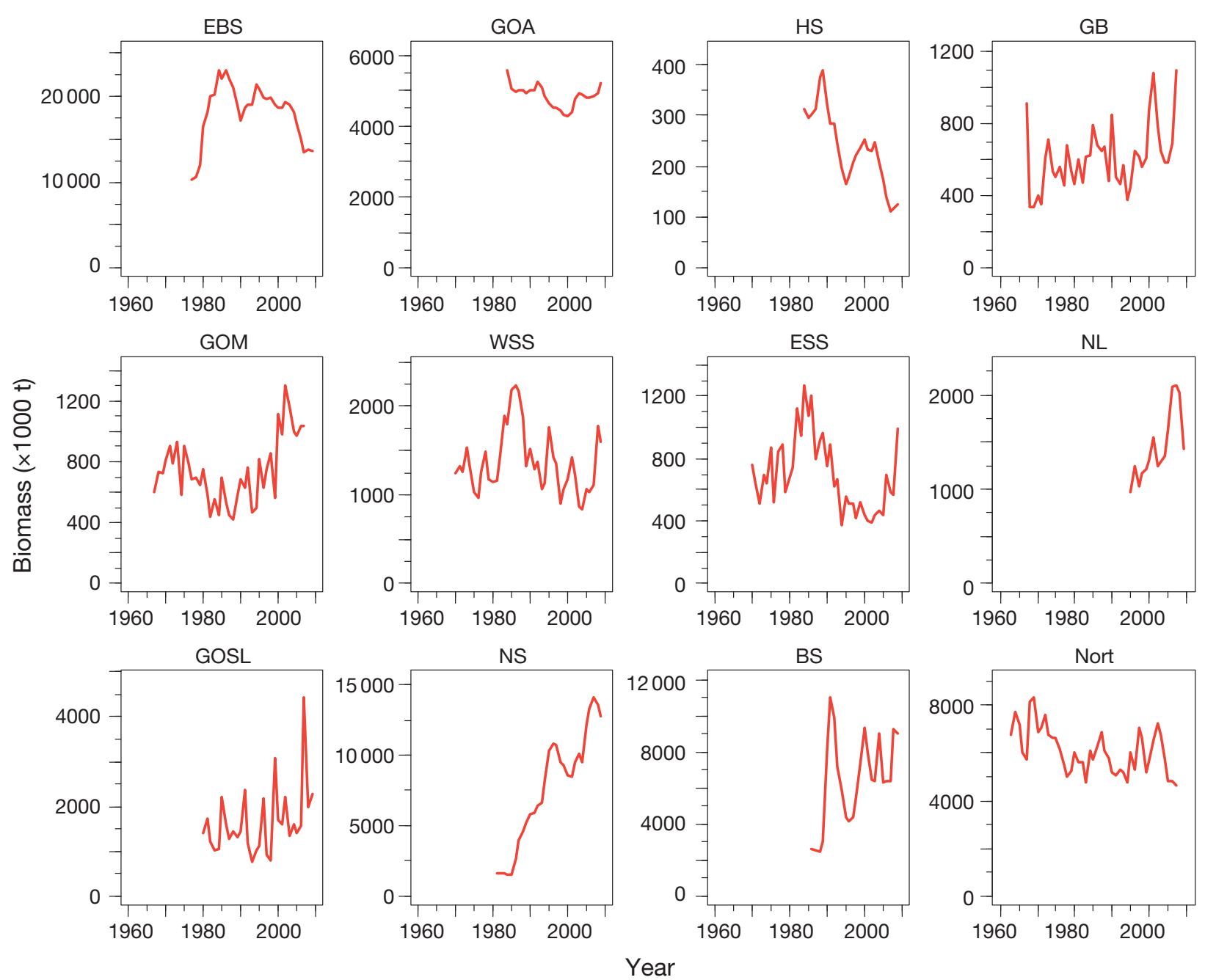

Fig. 1. Total aggregate biomass in each system. See Table 1 for system abbreviations

sion models, time lags before effects on $r$ were realized for the best-fit models were typically 4 yr or less. In this case, only 1 to 2 covariates improved the model fits in each system, most of which reflect temperature conditions.

\section{Comparison of regression (ASP) and dynamic model results, with and without covariates}

In most cases where the inclusion of a covariate improved the model fit to the data (Table 2), the best environmental covariates for the dynamic models were the same as or similar to those for the regression models (Table 2). In 3 cases they were differentGulf of Maine, western Scotian Shelf, and Norwegian Sea; on the western Scotian Shelf, for example, the biomass index of grey seals provided the best fit for the dynamic model, but was not included among the 2 covariates that improved the fit of the regression model $(\mathrm{p}<0.05)$.

With the exception of the Gulf of Alaska, water temperature was an important covariate in all systems and most models in Table 2, either as SST or temperature at depth. Large-scale climatological signals such as the North Atlantic Oscillation (NAO), Pacific Decadal Oscillation (PDO), or Atlantic Multidecadal Oscillation (AMO) increased the fit of the model to the data for 7 ecosystems, and were the most important covariate in 4 of the regression models and 1 dynamic model. In some systems, local covariates were important, such as a measure of sea ice in the Barents Sea, the Siberian/Alaskan Index in the eastern Bering Sea, a composite index in Newfoundland-Labrador, winter average sea surface height in Hecate Strait, and water stratification on the western and eastern Scotian Shelf. In 3 ecosystems, a biological predator covariate improved the 

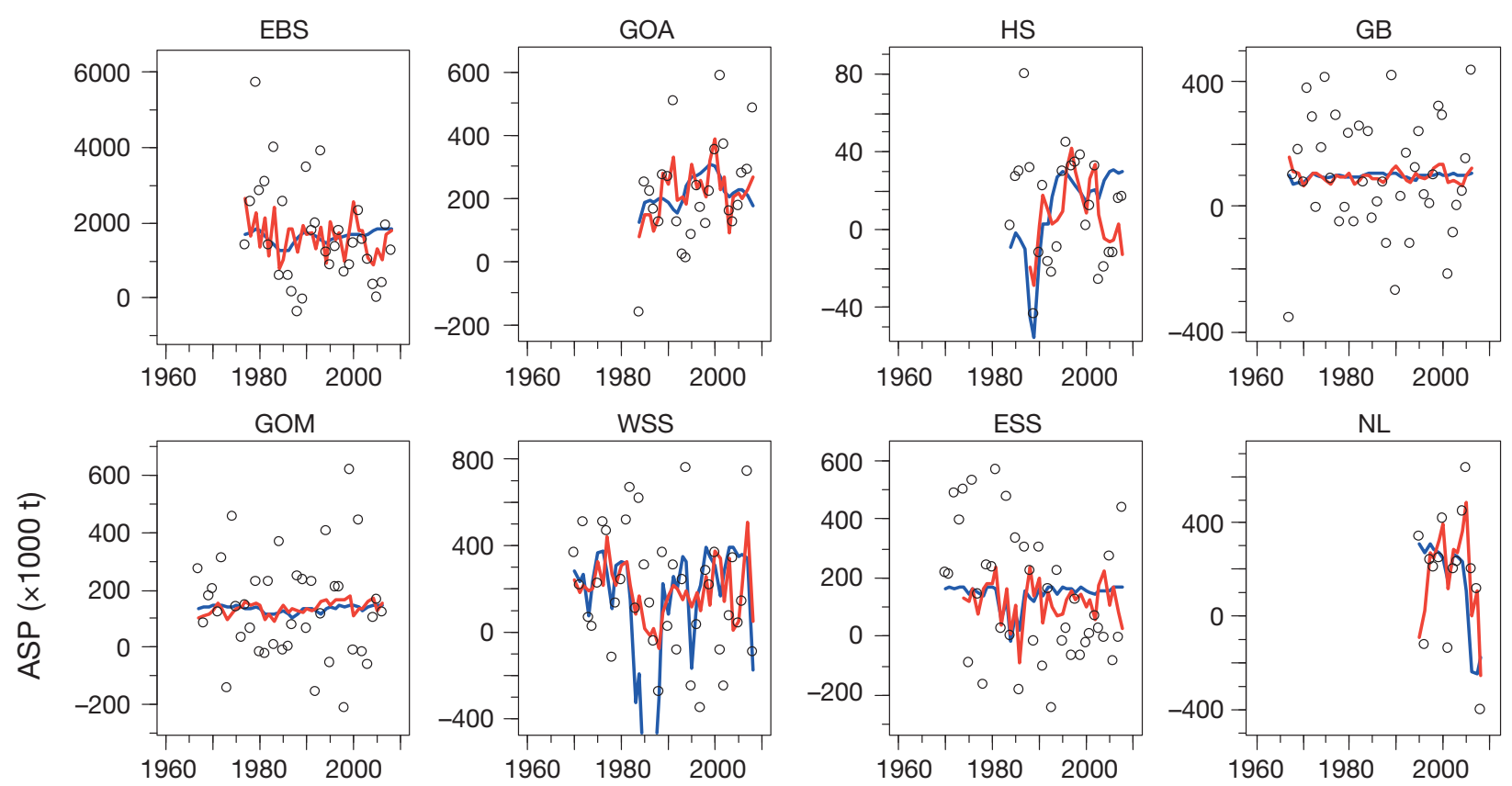

Fig. 2. Observed (unfilled circles) and predicted annual surplus production (ASP) based on regression model of ASP without (blue) and with (red) best environmental covariates (Table 2). See Table 1 for system abbreviations. Note that GOSL was dropped from the analysis since neither the regresssion nor the dynamic model was able to produce credible estimates of maximum sustainable yield
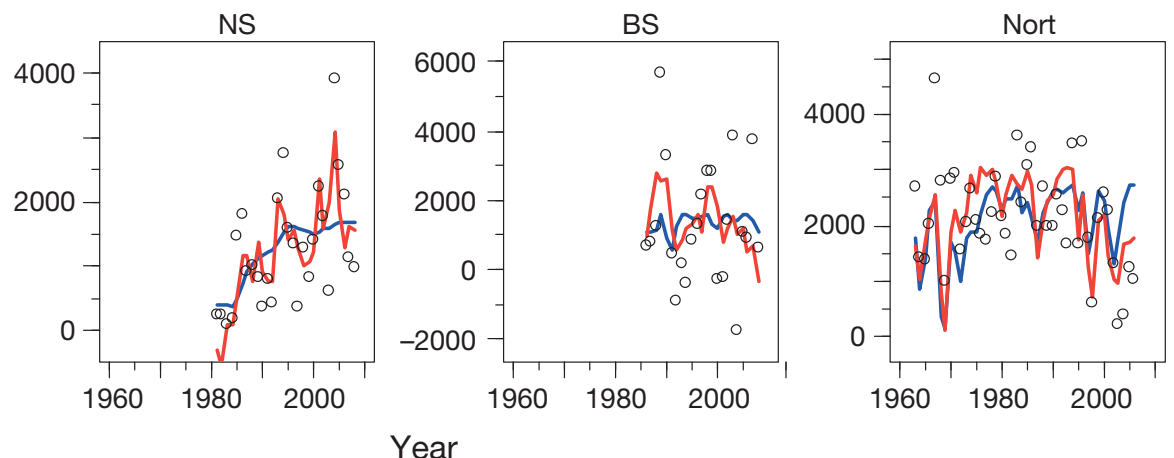

model fit: the biomass index of grey seals on the eastern Scotian Shelf (both models) and on the western Scotian Shelf (dynamic model), and biomass of arrowtooth flounder in Hecate Strait (both models).

When compared across all 4 models, the estimated MSY per unit area (Fig. 5a) differed statistically among systems (weighted 2-way ANOVA: $F_{11,33}=$ $43.9, \mathrm{p}<0.001)$ as well as among models $\left(F_{3,33}=8.18\right.$, $\mathrm{p}<0.001)$. Overall estimates largely ranged between 1 and $5 \mathrm{t} \mathrm{km}^{-2}$ (20th percentile $=1.22$, 80th percentile $=5.28)$. Furthermore, in several cases, MSY per unit area estimates were relatively consistent across the 4 models, i.e. Barents Sea, Norwegian Sea, and Gulf of Maine. In other cases, the addition of the covariate term made a large difference to MSY, such as Hecate Strait (38\%, regression model), western Scotian Shelf (56\%, dynamic model), eastern Scotian Shelf (63\%, dynamic model), and Newfoundland-Labrador (43\%, dynamic model). However, the sensitivity of the results to the method used was moderate, as the rank of the ecosystems' MSY per area was largely in-

dependent of the method: North Sea, eastern Bering Sea, and western Scotian Shelf were always in the top 50\%, and Hecate Strait, NewfoundlandLabrador, eastern Scotian Shelf, and Gulf of Alaska were always in the bottom $50 \%$; other systems were intermediate.

Estimates of $F^{\prime}$ MSY also differed statistically across ecosystems $\left(F_{11,33}=48759, \mathrm{p}<0.001\right)$, but not across models $(F=0.0563, \mathrm{p}=0.982 ;$ Fig. 5b). Estimates of $F_{\text {MSY }}^{\prime}$ were substantially higher for Georges Bank and North Sea than for the other systems, which ranged between 0.1 and $0.4 \mathrm{yr}^{-1}$.

Estimates of $B_{\mathrm{MSY}}$ generally range between 5 and $15 \mathrm{t} \mathrm{km}^{-2}$, although lower values occurred in Newfoundland-Labrador and the highest values occurred in eastern Bering Sea (Fig. 5c).

Thus, variability notwithstanding, the biological parameter estimates from each method, with or without covariates (Fig. 5), indicate that MSY is largely between 1 and $5 \mathrm{t} \mathrm{km}^{-2}$, that the optimal exploitation rate $\left(F_{\mathrm{MSY}}^{\prime}\right)$ is between 0.1 and $0.4 \mathrm{yr}^{-1}$, and $B_{\mathrm{MSY}}$ gen- 

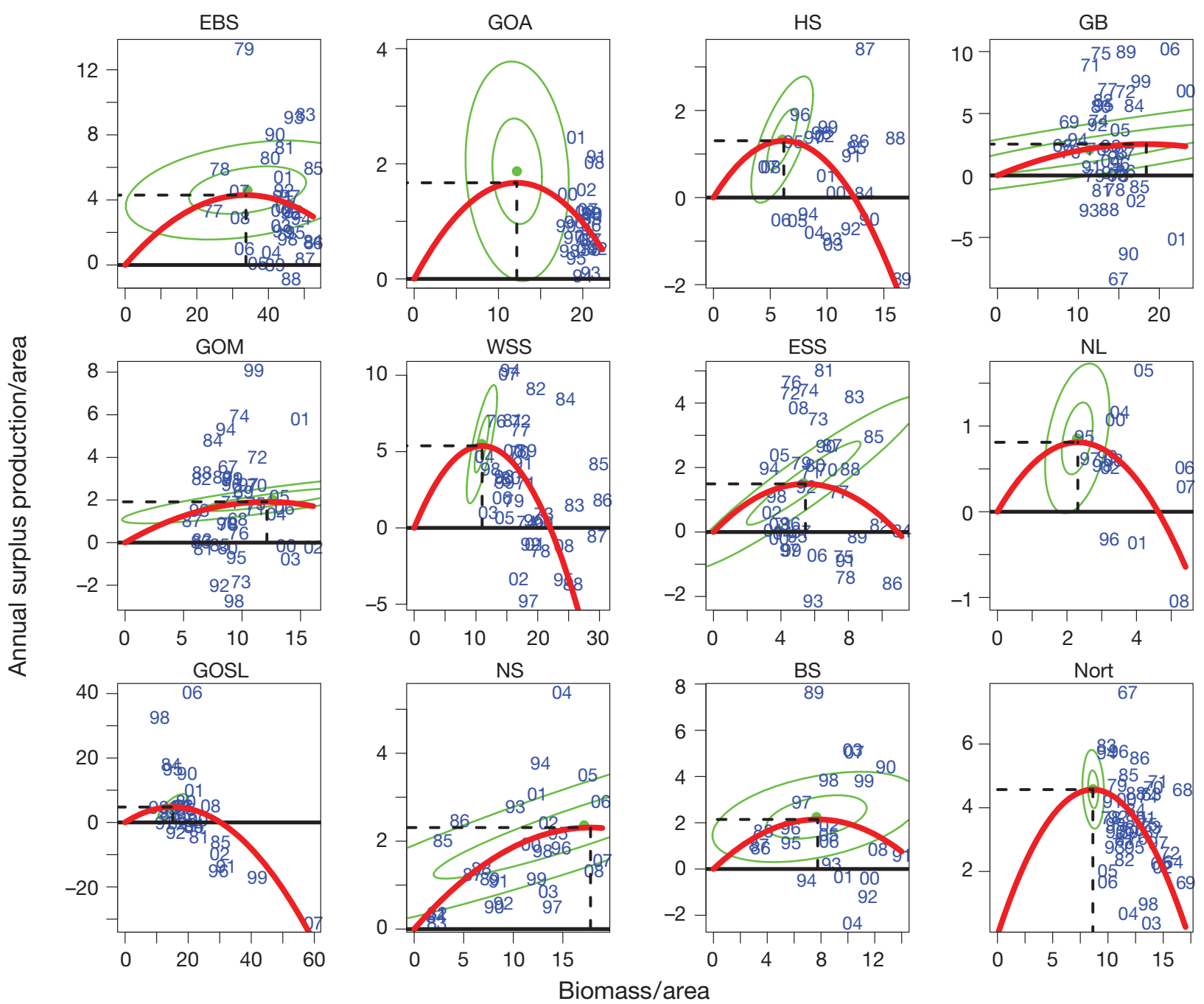

Fig. 3. Observed (blue numbers, labeled by year) and predicted annual surplus production (ASP) from the regression model (red line). All models includes a first-order autocorrelation term, except ESS for which the model failed when including such a term. The horizontal and vertical dotted lines represent, respectively, the MSY (the maximum sustainable yield) and the $B_{\mathrm{MSY}}$ (the biomass at which MSY occurs). Green ellipses represent uncertainty of $B_{\mathrm{MSY}}$ and MSY, calculated based on the variancecovariance matrix of the model; the inner and the outer ellipse is expected to contain the real $B_{\mathrm{MSY}}$ and MSY with a probability of 0.5 and 0.95 , respectively. See Table 1 for system abbreviations

erally ranges between 5 and $15 \mathrm{t} \mathrm{km}^{-2}$. An exception is the Norwegian Sea, which shows a considerably higher optimal exploitation rate (0.6 to $1.2 \mathrm{yr}^{-1}$, depending on the method).

\section{MSY and number of species}

In order to exclude the possibility that MSY was influenced by the number of species included in each model (Table 1; Table $\mathrm{S} 1$ in the supplement), we tested the relationship between MSY per area and the number of species represented in each modeled ecosystem, but found no relationship (regression model without covariates: $\mathrm{R}^{2}<0.001$, with covariates: $\mathrm{R}^{2}=0.029$; dynamic model without covariates: $\mathrm{R}^{2}=$ 0.008 , with covariates: $\mathrm{R}^{2}=0.041$ ).

\section{MSY and productivity}

We found no relationship between MSY per unit area and ordinary measures of productivity ( $\mathrm{chl} a$ concentration and PP); nor did MSY seem to be related to mean wind speed (Fig. S2 in the supplement). There was a possible positive relationship between the flux of chlorophyll and MSY for 3 out of 4 MSY estimates, but the relationships were not sta- 
Table 2. Best environmental covariates (based on improved model fit as well as most reasonable or least uncertain parameter values) for regression models of annual surplus production (ASP) and for biomass dynamic models. The best fitting covariate is listed first. Covariates in bold improved the fit of both models. Column 1 shows time lag between the covariate and the effect in the model, which was varied between 1 and $7 \mathrm{yr}$, fitted model parameters are $\delta$ (magnitude and sign of effect of the covariate on ASP) and $\gamma$ (magnitude and sign of effect of the covariate on population growth), and $\Delta \mathrm{AIC}_{\mathrm{c}}$ is the difference in Akaike information criterion (AIC $\mathrm{C}_{\mathrm{c}}$ ) between models with covariates and models without (Hurvich \& Tsai 1989, Burnham \& Anderson 2002). AMO: Atlantic Multidecadal Oscillation, avg.: average, NAO: North Atlantic Oscillation, nd: not determined, PDO: Pacific Decadal Oscillation, SST: sea surface temperature, temp.: temperature. See Table 1 for system abbreviations

\begin{tabular}{|c|c|c|c|c|c|c|c|c|}
\hline \multirow{2}{*}{ System } & \multicolumn{4}{|c|}{ Regression model } & \multirow{2}{*}{ Covariate Dynamic model } & \multirow[b]{2}{*}{1} & \multirow[b]{2}{*}{$\gamma$} & \multirow[b]{2}{*}{$\Delta \mathrm{AIC}_{\mathrm{c}}{ }^{\mathrm{a}}$} \\
\hline & Covariate & 1 & $\delta$ & $\Delta \mathrm{AIC}_{\mathrm{C}}{ }^{\mathrm{a}}$ & & & & \\
\hline EBS & Summer avg. SST & 1,7 & -517.3 & -3.43 & Siberian/Alaskan Index & 1 & -0.82 & -7.1 \\
\hline & $\mathrm{PDO}$ & 7 & -502.0 & -2.03 & Summer avg. SST & 1 & -0.63 & -6.9 \\
\hline GOA & PDO & 0 & -68.8 & -3.33 & & & & \\
\hline HS & Biomass index of arrowtooth flounder & r 4 & -21.3 & -6.69 & Biomass index of arrowtooth flounder & 4 & -1.48 & -13.5 \\
\hline & Winter avg. SST & 4 & 10.3 & -2.86 & Winter avg. surface height & 1 & -2.11 & -3.9 \\
\hline GB & Annual avg. SST & 2 & -21.1 & -2.58 & Annual avg. SST & 5 & 0.24 & -12.3 \\
\hline GOM & NAO index & 3 & 21.5 & -4.24 & Annual avg. SST & 3 & $\begin{array}{r}-0.18 \\
0.11\end{array}$ & -2.0 \\
\hline WSS & $\begin{array}{l}\text { Annual avg. water temp. at } 50 \mathrm{~m} \\
\text { Annual avg. stratification } \\
\text { NAO index }\end{array}$ & $\begin{array}{l}1 \\
3 \\
7\end{array}$ & $\begin{array}{l}103.9 \\
-93.6 \\
-91.0\end{array}$ & $\begin{array}{l}-3.25 \\
-2.28 \\
-2.06\end{array}$ & Biomass index of grey seals & 0 & -0.62 & $\mathrm{nd}^{\mathrm{b}}$ \\
\hline ESS & $\begin{array}{l}\text { Annual avg. water temp. at bottom } \\
\text { Biomass index of grey seals } \\
\text { Annual avg. water temp. at } 50 \mathrm{~m}\end{array}$ & $\begin{array}{c}4,6 \\
0,1,2 \\
3\end{array}$ & $\begin{array}{r}56.7 \\
-101.5 \\
81.8\end{array}$ & $\begin{array}{l}-4.11 \\
-3.47 \\
-3.29\end{array}$ & Biomass index of grey seals & 0 & -1.92 & $\mathrm{nd}^{\mathrm{b}}$ \\
\hline NL & $\begin{array}{l}\text { Composite of environmental indices } \\
\text { NAO index } \\
\text { Avg. SST (Stn 27) }\end{array}$ & $\begin{array}{l}1 \\
5 \\
2\end{array}$ & $\begin{array}{l}230.0 \\
189.7 \\
237.8\end{array}$ & $\begin{array}{l}-6.02 \\
-4.20 \\
-3.76\end{array}$ & & & & \\
\hline NS & AMO & 6 & 638.3 & -12.58 & $\begin{array}{l}\text { Annual avg. SST } \\
\text { NAO index }\end{array}$ & $\begin{array}{l}5 \\
1\end{array}$ & $\begin{array}{r}0.65 \\
-0.30\end{array}$ & $\begin{array}{c}\mathrm{nd}^{\mathrm{b}} \\
-3.3\end{array}$ \\
\hline $\mathrm{BS}$ & Annual avg. temp. & 2,3 & -893.0 & -7.4 & $\begin{array}{l}\text { Index of sea ice cover } \\
\text { Annual avg. temp. }\end{array}$ & $\begin{array}{l}6 \\
4\end{array}$ & $\begin{array}{r}0.76 \\
-0.57\end{array}$ & $\begin{array}{l}-19.5 \\
-17.5\end{array}$ \\
\hline Nort & $\begin{array}{l}\text { AMO } \\
\text { Annual avg. surface water temp. }\end{array}$ & $\begin{array}{c}0 \\
0,1\end{array}$ & $\begin{array}{l}-513.7 \\
-384.2\end{array}$ & $\begin{array}{l}-8.32 \\
-6.55\end{array}$ & $\begin{array}{l}\text { NAO index } \\
\text { AMO }\end{array}$ & $\begin{array}{l}1 \\
0\end{array}$ & $\begin{array}{l}-0.12 \\
-0.24\end{array}$ & $\begin{array}{l}-24.4 \\
-24.4\end{array}$ \\
\hline
\end{tabular}

tistically significant ( $\mathrm{p}$-values from 0.07 to 0.18 ). Since we observed a tendency for larger areas to have higher MSY per area in these results, we further explored the potential relationship between MSY and productivity using multiple linear regression with ecosystem area as a second covariate. There appeared to be a joint effect for the mass flux index with ecosystem area; mass flux had a significant positive effect $(p<0.05)$ on MSY for 3 of the 4 MSY estimates (Fig. 6).

\section{DISCUSSION}

Our results highlight several novel findings: (1) MSY is largely between 1 and $5 \mathrm{t} \mathrm{km}^{-2}$, (2) the optimal exploitation rate $F_{\text {MSY }}^{\prime}$ is between 0.1 and $0.4 \mathrm{yr}^{-1}$, (3) $B_{\mathrm{MSY}}$ varies between 5 and $15 \mathrm{t} \mathrm{km}^{-2}$, (4) the environment, specifically water temperature, notably affects estimates of MSY across most ecosystems studied, and (5) the relationship between fisheries yield and PP is not as simple as suggested in other studies (Iverson 1990, Ware \& Thomson 2005, Chassot et al. 2007). Our analyses give some new insights into the similarities and differences among ecosystems, and suggest that reasonable and consistent estimates of system-level MSY can be obtained, which can provide useful ecosystem-level reference points. We discuss each of these findings in further detail below.

\section{A reasonably consistent picture}

Although there was surprising consistency in the estimated reference points, there was some variation 

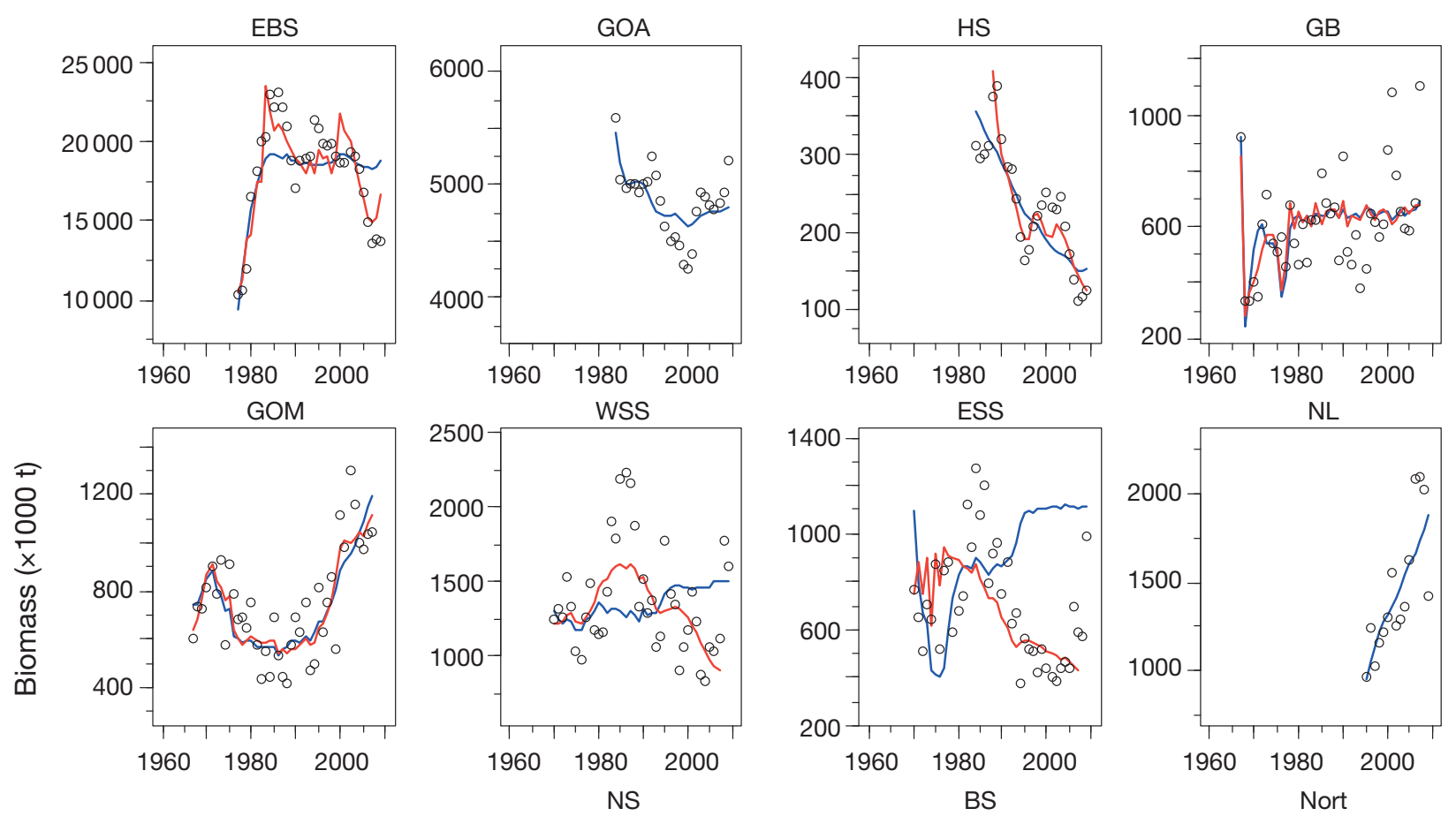

Fig. 4. Observed (unfilled circles) and predicted biomass from dynamic model without (blue line) and with (red line) best environmental covariates (see Table 2). For GOA and NL, no covariates improved the dynamic model fit. See Table 1 for system abbreviations
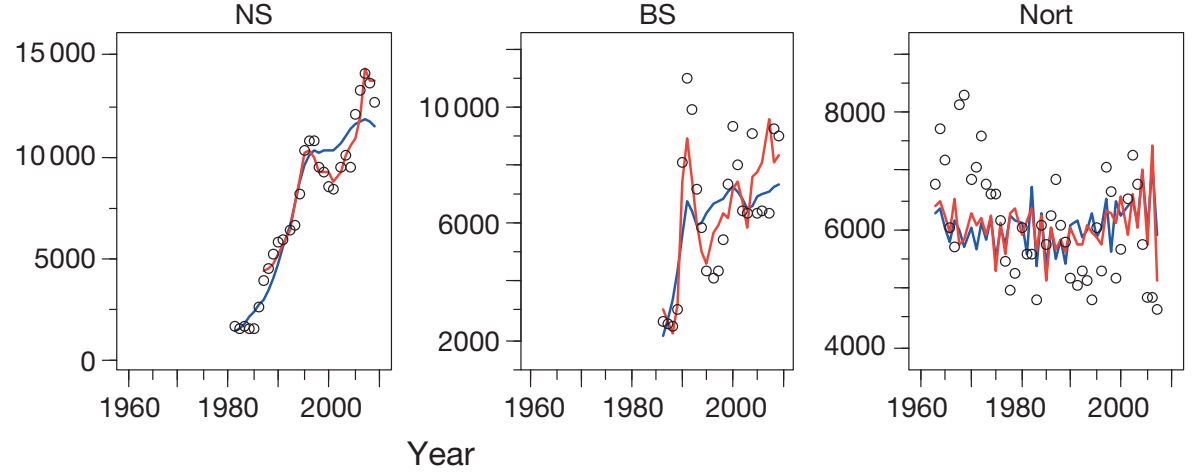

among models and ecosystems. This is to be expected because the ecosystems modeled had different fishing histories, different data sources (assessment or survey-based), and different lengths of time series. The regression and dynamic models yielded different results for a few ecosystems, which increased when covariates were added, but overall provided a reasonably consistent picture across methods, strengthening our conclusions. We note that including or excluding covariates had a significant effect on parameter estimates. However, the sensitivity of the results to the method used was moderate, as the relative magnitude and rank of the ecosystems' MSY per area was largely independent of the method. Where there were differences, the data pattern may have had a large influence on the robustness of the estimates.

We recognize that the aggregated surplus production models, like all models, are oversimplifications because they treat the entire fish community as a single, aggregated 'population', model the dynamics of this aggregate 'population' using an average growth rate and carrying capacity that is invariant to age structure and species composition, and assume that there is no change in productivity or carrying capacity over time. The latter point is important for the eastern Canadian systems, which have all undergone a potential regime shift (Benoît \& Swain 2008, Bundy et al. 2009, Shackell et al. 2010, DFO 2011). An examination of empirical estimates of surplus production provides a useful tool to detect and better understand such changes in productivity (Walters et al. 2005). Future work should explore the effect of changes in productivity on MSY and other BRPs or harvest control rules (Mohn \& Chouinard 2007, Brunel et al. 2010).

\section{Common drivers at the basin scale}

In most ecosystems, the model fits to the data were improved by adding a covariate. Water temperature 

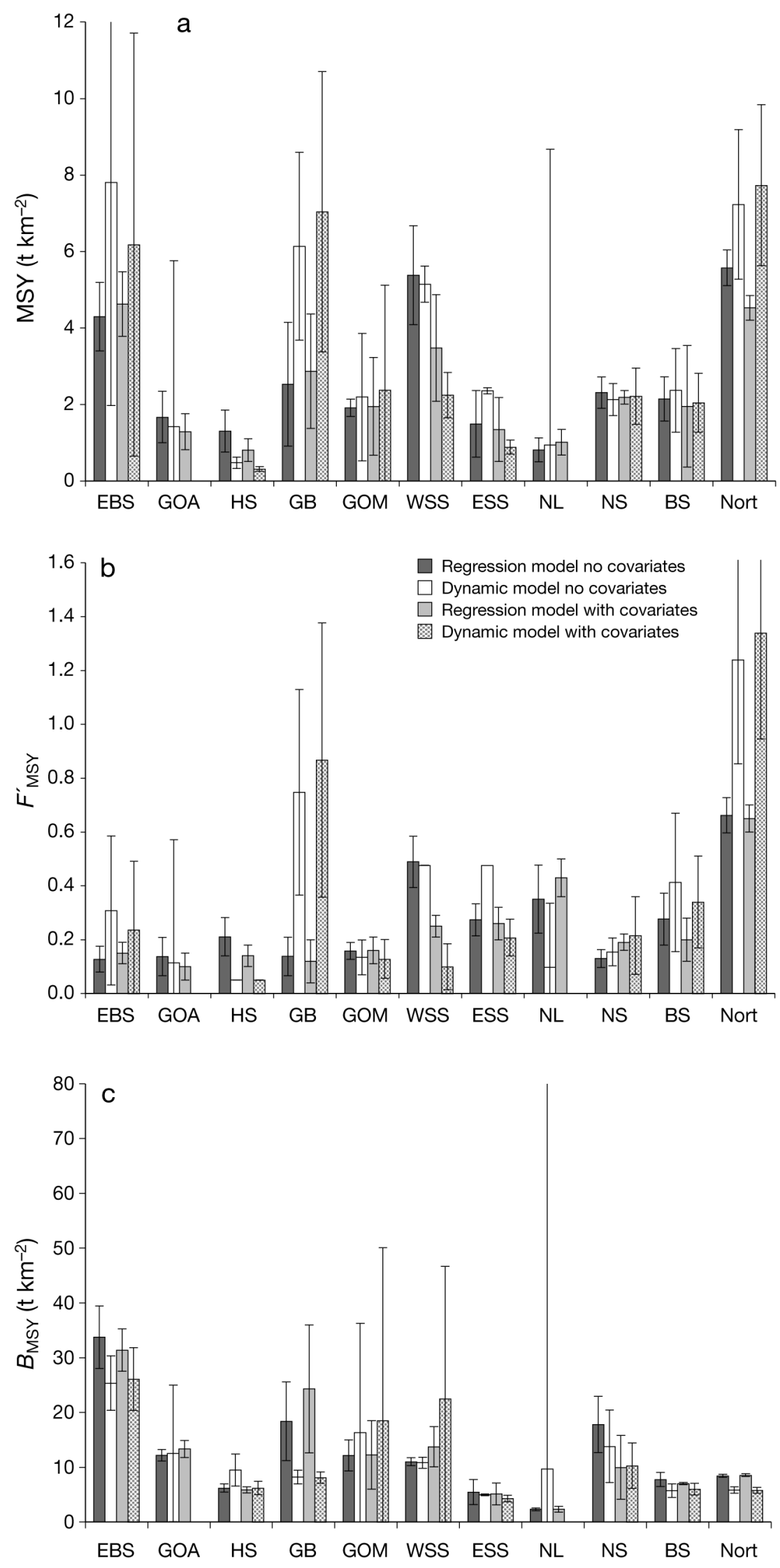

improved either or both model fits for all ecosystems, except the Gulf of Alaska. At a basin scale, in the North Pacific the PDO improved the fit of the eastern Bering Sea (regression) and Gulf of Alaska (regression) models, and the Siberian/Alaskan Index, reflecting ice conditions in the Bering Sea, was significant only in the eastern Bering Sea dynamic model. In the NW Atlantic, the NAO improved the model fits for 3 of the 5 ecosystems (Gulf of Maine, eastern Scotian Shelf, Newfoundland-Labrador regression models), but the AMO did not improve the fit for any NW Atlantic ecosystem. In the NE Atlantic, the NAO and AMO also improved the fit for 2 of the 3 ecosystems. Thus these large-scale oceanographic indices (that largely reflect water temperature variability) may influence ecosystem dynamics and productivity over the whole North Atlantic basin. In addition, more local environmental influences were important for most ecosystems. In particular, the Hecate Strait models were most influenced by the predator biomass and winter average sea surface height, a local composite index (Colbourne et al. 2010) improved the fit of the Newfoundland-Labrador regression models, and sea ice was the most important covariate in the Barents Sea (dynamic model). Since the inclusion of a covariate had a substantial effect on MSY in some cases (e.g. western Scotian Shelf), understanding the importance of different environmental covariates on system productivity could lead to improved management by developing robust models, such as those developed here, to take environmental effects into consideration when determining reference points and setting overall quotas.

Fig. 5. (a) Maximum sustainable yield (MSY) per area, (b) exploitation rate at $\operatorname{MSY}\left(F_{M S Y}^{\prime}\right)$, and (c) biomass at MSY $\left(B_{\mathrm{MSY}}\right)$ per area, for each region and for each method. Results $(\mathrm{a}, \mathrm{c})$ from the best-fitting covariates for each model (see Table 2). Error bars indicate $1 \mathrm{SD}$. See Table 1 for system abbreviations 


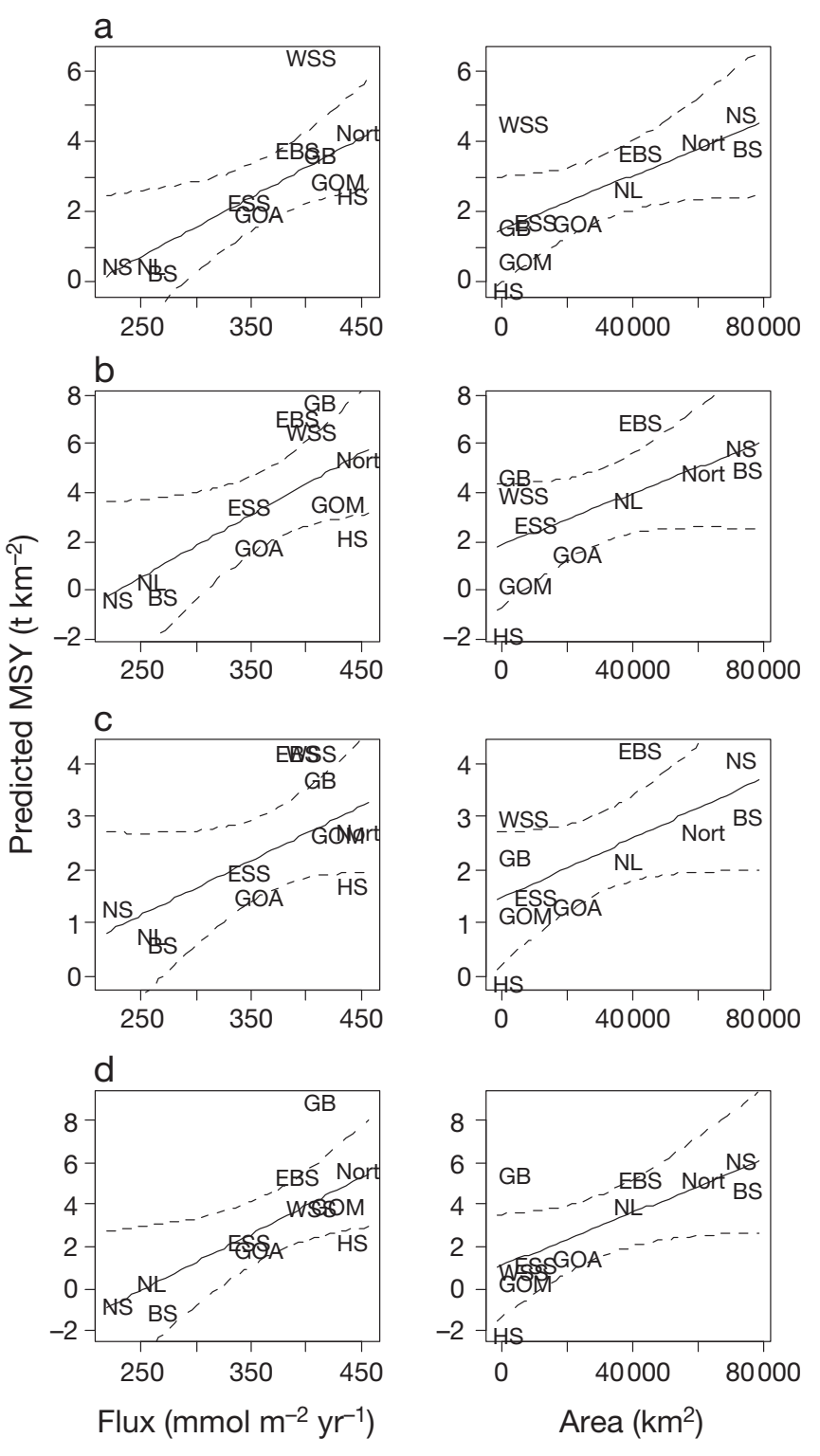

Fig. 6. Multiple linear regression results for maximum sustainable yield (MSY) per area as a function of ecosystem area (right panels) and mass flux index (left panels) under (a) regression model (no covariates), (b) dynamic model (no covariates), (c) regression model (with covariates), and (d) dynamic model (with covariates). Solid and dotted lines represent linear regressions and their $95 \%$ confidence intervals, respectively. See Table 1 for system abbreviations

\section{Impact of covariates on BRPs and implications for fisheries management}

Surplus production models, like most stock assessment models, assume stationarity in productivity. Violations of this assumption are common and can lead to biases in BRPs estimated from stock-recruitment dynamics (Parma 1990) or from surplus production dynamics (Walters et al. 2005). Empirical estimates of surplus production such as those used here can provide insights into processes causing non-stationarity (Walters et al. 2005), and environmental covariates can be included into surplus production models to account for non-stationarity and to obtain improved reference points (Jacobson et al. 2005). In the absence of a priori hypotheses, we used an exploratory approach to assess the influence of selected environmental variables of surplus production dynamics and found strong evidence that aggregate surplus production is linked to environmental variability.

In those cases where the covariate improved the model's fit to the biomass data for the dynamic model (i.e. eastern Bering Sea, Hecate Strait, western Scotian Shelf, and eastern Scotian Shelf), the inclusion of a covariate resulted in a lower MSY (under average conditions) than in the model without a covariate. In the case of the eastern Bering Sea, increased temperatures after the 1976-1977 regime shift were associated with reduced sea ice cover, and both temperatures and sea ice conditions have shown pronounced variability in the last decade (Hunt et al. 2011). Recent high-temperature, low-ice conditions had a negative impact on the recruitment of species such as cod and pollock in the eastern Bering Sea and Gulf of Alaska (Mueter et al. 2009, 2011), which will affect overall fish production and may result in decreased MSY if temperatures increase in the future. In the other 3 models, the addition of a major predator as the covariate improved the fit of the model and decreased MSY. In Hecate Strait, arrowtooth flounder is a voracious predator whose diet consists of $75 \%$ fish (Pearsall \& Fargo 2007). For the period from 1984 to 2009, it comprised $41 \%$ of the predator biomass of herring (Schweigert et al. 2010). The fit of the western Scotian Shelf and eastern Scotian Shelf models was improved with the addition of grey-seal biomass as a covariate. Grey seals are a top predator on the eastern Scotian Shelf (Bundy 2005, Trczinski et al. 2009) and their distribution is expanding to the western Scotian Shelf (Trzcinski et al. 2009, DFO 2011). The trophic role of grey seals and the extent to which they are responsible for the non-recovery of groundfish stocks has been the subject of considerable controversy on the Scotian Shelf (DFO 2011), in the Gulf of St. Lawrence, and in NewfoundlandLabrador. Interestingly, seal biomass did not improve the model fits in Newfoundland-Labrador.

The time lag of the environmental variables was in most cases less than 3 to 4 yr. Time lags of 1 yr indicate that the environment affects the somatic growth of fish, while time lags $>1$ yr can be the result of the 
environment affecting recruitment. In the latter case we would expect the environment to have the largest impact on the early juvenile stages, hence changes in biomass will be apparent 2 to 4 yr later when a cohort first becomes fully or largely vulnerable to the survey gear or is first included in the assessment. A few time lags were somewhat longer than expected from this mechanism and further examination is warranted to tease apart the mechanisms underlying them.

We recommend that aggregate MSY could be considered an overall limit for total removals from an ecosystem, and that the cumulative MSY of individual stocks should not exceed it, as suggested by other studies (Brown et al. 1976, Walters et al. 2005, Mueter \& Megrey 2006, Tyrrell et al. 2011) and similar to the existing caps on total removals in the Bering Sea and Gulf of Alaska (Witherell et al. 2000). Further, we would suggest that the aggregate MSY should be exploited in a 'balanced' way, across stocks in relation to their productivity (Bundy et al. 2005, Zhou et al. 2010, Garcia et al. 2011, 2012). This could first be explored using surplus production models at different levels of aggregation (see Fogarty et al. 2012, this Theme Section, Gaichas et al. 2012b, this Theme Section, Holsman et al. 2012b, this Theme Section, Lucey et al. 2012, this Theme Section). Aggregate limits can provide an additional tool for managers to prevent ecosystem overfishing, in combination with single-species limits that are required to prevent the loss of the least common (or most easily caught) fish species, or those with lower intrinsic growth rate (Worm et al. 2009, Garcia et al. 2011, Gaichas et al. 2012b).

\section{MSY and PP}

Our results suggest a useful rule of thumb for MSY in the northern hemisphere: MSY appears to vary between 1 to $5 \mathrm{t} \mathrm{km}^{-2}$ for these ecosystems. This variation is approximately as large as the variation in average phytoplankton concentrations (which varies up to 7 -fold among systems), but contrary to what we expected, MSY does not vary consistently with phytoplankton concentration nor with estimated PP. However, if we exclude Hecate Strait from the analysis (an obvious outlier), a positive relationship between chlorophyll concentration and MSY emerged, but most of the variation in MSY is still unexplained. This contrasts with the findings of Iverson (1990), Ware \& Thomson (2005), and Chassot et al. (2007), who found that realized fisheries yield per area varies linearly with PP and/or with chlorophyll concentration. How- ever, other studies (e.g. Sherman et al. 2009, Chassot et al. 2010, Conti \& Scardi 2010, Friedland et al. 2012) also failed to find a close relationship between PP and fisheries yield; Chassot et al. (2010) found that 3 additional factors - the probability of an ecosystem being sustainably fished ( $P_{\text {susti }}$ Libralato et al. 2008), average maximum length of fish, and ecosystem type - were required to explain $77 \%$ of the variability in catch across LMEs globally (measured as PP required, PPR; Pauly \& Christensen 1995). They found a tighter relationship between catch and PP when catch was expressed as PPR. It is possible that if we calculated MSY as PPR, we might find similar results: however, it is not possible to disaggregate the aggregate production estimate of MSY into MSY per trophic level with the models used here. Friedland et al. (2012) also noted that the relationship between lower-trophiclevel dynamics and pathways with fisheries yield is not a straightforward linear relationship with standing phytoplankton biomass.

We challenge previous findings that suggest a simple linear relationship between catch and PP (see also Frank et al. 2006). Our exploratory analyses suggest that MSY increases with total ecosystem area and the mass flux index. The latter index measures the mass flux of POC (Honjo et al. 2008, Friedland et al. 2012); a high value indicates that much of the energy produced by primary producers is transferred to mesozooplankton and thereby to higher trophic levels. Ecosystems characterized by strong thermal transitions and pronounced blooms will tend to have high values of POC flux. Thus, a positive relationship between maximum production and the mass flux index is consistent with the hypothesis that efficient energy transport from primary producers to higher trophic levels is more important than high PP per se.

In conclusion, we compared aggregate system production models across 12 northern hemisphere ecosystems to explore likely production caps for aggregate commercial species. We assert that total species-specific MSYs should be managed within this aggregate limit to reduce the risk of ecosystem overfishing (Murawski 2000), using a balanced harvesting approach (Garcia et al. 2012). That the triad of drivers explored here influences MSY and productivity is not surprising; that environmental drivers were almost always important was surprising. Importantly, although in some cases the 2 models (regression and dynamic) produced different estimates, there was reasonable consistency among the covariates that were important for model fit, relative magnitude of outputs, and the rank ordering of systems by each model. Since in most cases where the inclu- 
sion of a covariate significantly improved model fit it resulted in reduction of MSY, we strongly recommend that environmental and trophic covariates be explored when estimating MSY for management purposes (see also Link et al. 2012). These results have implications for fisheries management (Walters et al. 2005) and an ecosystem approach to management (Murawski 2007, Link 2010, Belgrano \& Fowler 2010), particularly in the context of changing sea water temperatures as a result of climate change (Belkin 2009).

Acknowledgements. We thank Kevin Friedland (National Marine Fisheries Service [NMFS]) for providing the mass flux index, and the Ocean Biology Processing Group of NASA for the distribution of SeaWiFS data. This collaborative, multilateral work was funded through the US Comparative Analysis of Marine Ecosystem Organization (CAMEO), the Norwegian Research Council (NRC), and Canada's Ecosystem Research Initiative (ERI). Major national institutes (Fisheries and Oceans Canada [DFO], Institute of Marine [IMR], and NMFS) also contributed significant in-kind and directed resources to this project. This work is also endorsed by Ecosystem Studies of Sub-Arctic Systems [ESSAS]. The work we report upon herein resulted from several joint meetings, particularly the Surplus Production Modeling Workshop (SPMW 1 \& 2) and associated inter-cessional efforts, representing a continuation of and follow-on to other joint workshops, including Canadian and US Ecosystems (CANUSE I \& II), Marine Ecosystems of Norway and the US (MENU I \& II), and Norwegian-Canadian Collaborations (NORCAN). We also thank the reviewers who provided some excellent advice, resulting in an improved manuscript. Finally, we dedicate this work to the memory of Bern Megrey, who was an integral part of these efforts and whose untimely death was unfortunate but whose enthusiasm for this work was invaluable.

\section{LITERATURE CITED}

ADMB Project (2009) AD Model Builder: automatic differentiation model builder. Developed by David Fournier. http://admb-project.org

> Behrenfeld MJ, Falkowski PG (1997) Photosynthetic rates derived from satellite-based chlorophyll concentration. Limnol Oceanogr 42:1-20

Belgrano A, Fowler CW (2010) Ecosystem-based management of marine fisheries. Cambridge University Press, Cambridge

Belkin IM (2009) Rapid warming of large marine ecosystems. Prog Oceanogr 81:207-213

Benoît HP, Swain DP (2008) Impacts of environmental change and direct and indirect harvesting effects on the dynamics of a marine fish community. Can J Fish Aquat Sci 65:2088-2104

Branch TA, Jensen OP, Ricard D, Ye Y, Hilborn R (2011) Contrasting global trends in marine fishery status obtained from catches and from stock assessments. Conserv Biol 25:777-786

Brown BE, Brennan JA, Grosslein MD, Heyerdahl EG, Hennemuth RC (1976) The effect of fishing on the marine finfish biomass in the Northwest Atlantic from the Gulf of Maine to Cape Hatteras. ICNAF Res Bull 12:49-68
Brunel T, Piet GJ, van Hal R, Röckmann C (2010) Performance of harvest control rules in a variable environment. ICES J Mar Sci 67:1051-1062

$>$ Bundy A (2005) Structure and functioning of the eastern Scotian Shelf ecosystem before and after the collapse of groundfish stocks in the early 1990s. Can J Fish Aquat Sci 62:1453-1473

Bundy A, Fanning P, Zwanenburg KCT (2005) Balancing exploitation and conservation of the eastern Scotian Shelf ecosystem: application of a 4D ecosystem exploitation index. ICES J Mar Sci 62:503-510

Bundy A, Chuenpagdee R, Jentoft S, Mahon R (2008) If science is not the answer, what is? An alternative governance model for the world's fisheries. Front Ecol Environ 6:152-155

> Bundy A, Heymans JJ, Morissette L, Savenkoff C (2009) Seals, cod and forage fish: a comparative exploration of variations in the theme of stock collapse and ecosystem change in four northwest Atlantic ecosystems. Prog Oceanogr 81:188-206

Bundy A, Shannon LJ, Rochet MJ, Neira S, Shin YJ, Hill L, Aydin K (2010) The good(ish), the bad and the ugly: a tripartite classification of ecosystem trends. ICES J Mar Sci 67:745-768

Burnham KP, Anderson DR (2002) Model selection and multimodel inference: a practical information-theoretic approach, 2nd ed. Springer-Verlag, New York, NY

Chassot E, Melin F, Le Pape O, Gascuel D (2007) Bottom-up control regulates fisheries production at the scale of ecoregions in European seas. Mar Ecol Prog Ser 343:45-55

> Chassot E, Bonhommeau S, Dulvy NK, Mélin F, Watson R, Gascuel D, Le Pape O (2010) Global marine primary production constrains fisheries catches. Ecol Lett 13:495-505

Colbourne EB, Craig J, Fitzpatrick C, Senciall D, Stead P, Bailey W (2010) An assessment of the physical oceanographic environment on the Newfoundland and Labrador shelf in NAFO Subareas 2 and 3 during 2009. NAFO SCR Doc 10/16. Northwest Atlantic Fisheries Organization (NAFO), Dartmouth, NS

> Conti L, Scardi M (2010) Fisheries yield and primary productivity in large marine ecosystems. Mar Ecol Prog Ser 410: 233-244

> deYoung B, Heath M, Werner F, Chai F, Megrey B, Monfray $P$ (2004) Challenges of modeling ocean basin ecosystems. Science 304:1463-1466

DFO (Fisheries and Oceans Canada) (2011) Impacts of grey seals on fish populations in Eastern Canada. DFO Can Sci Advis Sec Sci Advis Rep 2010/071. DFO, Ottawa

FAO (Food and Agriculture Organization) (1978) Some scientific problems of multispecies fisheries. Report of the expert consultation on management of multispecies fisheries. FAO Fish Tech Pap 181. FAO, Rome

Fogarty MJ, Overholtz WJ, Link JS (2012) Aggregate surplus production models for demersel fishery resources of the Gulf of Maine. Mar Ecol Prog Ser 459:247-258

Frank KT, Petrie B, Shackell NL, Choi JS (2006) Reconciling differences in trophic control in mid-latitude marine ecosystems. Ecol Lett 9:1096-1105

> Frid CLJ, Paramor OAL, Scott CL (2006) Ecosystem-based management of fisheries: is science limiting? ICES J Mar Sci 63:1567-1572

Friedland KD, Stock C, Drinkwater KF, Link JS and others (2012) Pathways between primary production and fisheries yields of large marine ecosystems. PLoS ONE 7(1): e28945

Fu C, Gaichas S, Link JS, Bundy A and others (2012) Relative importance of fisheries, trophodynamic and environ- 
mental drivers in a series of marine ecosystems. Mar Ecol Prog Ser 459:169-184

Fukuda Y (1976) A note on yield allocation in multi-species fisheries. ICNAF Res Bull 12:83-87

Fulton EA, Smith ADM, Smith DC, van Putten IE (2011) Human behaviour: the key source of uncertainty in fisheries management. Fish Fish 12:2-17

Gaichas S, Skaret G, Falk-Petersen J, Link JS and others (2009) A comparison of community and trophic structure in five marine ecosystems based on energy budgets and system metrics. Prog Oceanogr 81:47-62

Gaichas SK, Bundy A, Miller TJ, Moksness E, Stergiou KI (2012a) What drives marine fisheries production? Mar Ecol Prog Ser 459:159-163

Gaichas SK, Gamble R, Fogarty M, Benoît H and others (2012b) Assembly rules for aggregate-species production models: simulations in support of management strategy evaluation. Mar Ecol Prog Ser 459:275-292

Garcia SM (ed), Kolding J, Rice J, Rochet MJ and others (2011) Selective fishing and balanced harvest in relation to fisheries and ecosystem sustainability. Report of a scientific workshop organized by the IUCN-CEM Fisheries Expert Group (FEG) and the European Bureau for Conservation and Development (EBCD) in Nagoya (Japan), 14-16 October 2010. IUCN, Gland, and EBCD, Brussels

Garcia SM, Kolding J, Rice J, Rochet MJ and others (2012) Reconsidering the consequences of selective fisheries. Science 335:1045-1047

Hare SR, Mantua NJ (2000) Empirical evidence for North Pacific regime shifts in 1977 and 1989. Prog Oceanogr 47: 103-145

Hilborn R, Walters C (1992) Quantitative fisheries stock assessment: choice, dynamics and uncertainty. Routledge, Chapman \& Hall, New York, NY

Holsman KK, Essington T, Miller TJ, Koen-Alonso M, Stockhausen WJ (2012) Comparative analysis of cod and herring production dynamics across 13 northern hemisphere marine ecosystems. Mar Ecol Prog Ser 459:231-246

Honjo S, Manganini SJ, Krishfield RA, Francois R (2008) Particulate organic carbon fluxes to the ocean interior and factors controlling the biological pump: a synthesis of global sediment trap programs since 1983. Prog Oceanogr 76:217-285

Hsieh CH, Glaser SM, Lucas AJ, Sugihara G (2005) Distinguishing random environmental fluctuations from ecological catastrophes for the North Pacific Ocean. Nature 435:336-340

> Hunt GL, Stabeno P, Walters G, Sinclair E, Brodeur RD, Napp JM, Bond NA (2002) Climate change and control of the southeastern Bering Sea pelagic ecosystem. DeepSea Res II 49:5821-5853

> Hunt GL, Coyle KO, Eisner LB, Farley EV and others (2011) Climate impacts on eastern Bering Sea foodwebs: a synthesis of new data and an assessment of the Oscillating Control Hypothesis. ICES J Mar Sci 68:1230-1243

Hurvich CM, Tsai CL (1989) Regression and time series model selection in small samples. Biometrika 76:297-307

> Iverson RL (1990) Control of marine fish production. Limnol Oceanogr 35:1593-1604

> Jacobson LD, De Oliveira JAA, Barange M, Cisneros-Mata MA and others (2001) Surplus production, variability, and climate change in the great sardine and anchovy fisheries. Can J Fish Aquat Sci 58:1891-1903

Jacobson LD, Bograd SJ, Parrish RH, Mendelssohn R, Schwing FB (2005) An ecosystem-based hypothesis for climatic effects on surplus production in California sardine (Sardinops sagax) and environmentally dependent surplus production models. Can J Fish Aquat Sci 62: 1782-1796

Jennrich RI (1995) An introduction to computational statistics: regression analysis. Prentice Hall, Englewood Cliffs, NJ

Kalnay E, Kanamitsu M, Kistler R, Collins W and others (1996) The NCEP/NCAR 40-year reanalysis project. Bull Am Meteorol Soc 77:437-471

Libralato S, Coll M, Tudela S, Palomera I, Pranovi F (2008) Novel index for quantification of ecosystem effects of fishing as removal of secondary production. Mar Ecol Prog Ser 355:107-129

Link JS (2010) Ecosystem-based fisheries management: confronting tradeoffs. Cambridge University Press, Cambridge

> Link JS, Stockhausen WT, Skaret G, Overholtz W and others (2009) A comparison of biological trends from four marine ecosystems: synchronies, differences, and commonalities. Prog Oceanogr 81:29-46

Link JS, Megrey BA, Miller TJ, Essington $\mathrm{T}$ and others (2010a) Comparative analysis of marine ecosystems: international production modelling workshop. Biol Lett 6:723-726

Link JS, Yemane D, Shannon LJ, Coll M, Shin YJ, Hill L, Borges MF (2010b) Relating marine ecosystem indicators to fishing and environmental drivers: an elucidation of contrasting responses. ICES J Mar Sci 67:787-795

Link JS, Gaichas S, Miller TJ, Essington T and others (2012) Synthesizing lessons learned from comparing fisheries production in 13 northern hemisphere ecosystems: emergent fundamental features. Mar Ecol Prog Ser 459: 293-302

Lucey SM, Cook AM, Boldt JL, Link JS, Essington TE, Miller TJ (2012) Comparative analyses of surplus production dynamics of functional feeding groups across 12 northern hemisphere marine ecosystems. Mar Ecol Prog Ser 459:219-229

$>$ Ludwig D, Walters CJ (1985) Are age structured models appropriate for catch-effort data? Can J Fish Aquat Sci 42:1066-1072

Ludwig D, Walters CJ (1989) A robust method for parameter estimation from catch and effort data. Can J Fish Aquat Sci 46:137-144

Mangel M (2006) The theoretical biologist's toolbox: quantitative methods for ecology and evolutionary biology. Cambridge University Press, Cambridge

May AW (1975) Report of standing committee on research and statistics. ICNAF 7th Spec Comm Meet (Sep 1975). International Commission for the Northwest Atlantic Fisheries (ICNAF), Dartmouth, NS

> Mayo RK, Fogarty MJ, Serchuk FM (1992) Aggregate fish biomass and yield on Georges Bank, 1960-1987. J Northwest Atl Fish Sci 14:59-78

> Mohn RK (1980) Bias and error propagation in logistic production models. Can J Fish Aquat Sci 37:1276-1283

> Mohn RK, Chouinard GA (2007) Harvest control rules for stocks displaying dynamic production regimes. ICES J Mar Sci 64:693-697

> Mueter FJ, Megrey BA (2006) Using multi-species surplus production models to estimate ecosystem-level maximum sustainable yields. Fish Res 81:189-201

Mueter FJ, Broms C, Drinkwater KF, Friedland KD and others (2009) Ecosystem responses to recent oceanographic variability in high-latitude Northern Hemisphere ecosystems. Prog Oceanogr 81:93-110

Mueter FJ, Bond NA, Ianelli JN, Hollowed AB (2011) Expected declines in recruitment of walleye pollock 
(Theragra chalcogramma) in the eastern Bering Sea under future climate change. ICES J Mar Sci 68: 1284-1296

Mullon C, Freon P, Cury P (2005) The dynamics of collapse in world fisheries. Fish Fish 6:111-120

Murawski SA (2000) Definitions of overfishing from an ecosystem perspective. ICES J Mar Sci 57:649-658

Murawski SA (2007) Ten myths concerning ecosystem approaches to marine resource management. Mar Policy 31:681-690

Murawski SA, Steele JH, Taylor P, Fogarty MJ, Sissenwine MP, Ford M, Suchman C (2010) Why compare marine ecosystems? ICES J Mar Sci 67:1-9

NRC (National Research Council USA) (1998) Improving fish stock assessments. National Academy Press, Washington, DC

Parma A (1990) Optimal harvesting of fish populations with non-stationary stock-recruitment relationships. Nat Resour Model 4:39-76

Pauly D, Christensen V (1995) Primary production required to sustain global fisheries. Nature 374:255-257

Pauly D, Trites AW, Capuli E, Christensen V (1998) Diet composition and trophic levels of marine mammals (vol 55, pg 467, 1998). ICES J Mar Sci 55:467-481

Pauly D, Christensen V, Guenette S, Pitcher TJ and others (2002) Towards sustainability in world fisheries. Nature 418:689-695

Pearsall IA, Fargo JJ (2007) Diet composition and habitat fidelity for groundfish assemblages in Hecate Strait, British Columbia. Can Tech Rep Fish Aquat Sci 2692

Pinheiro JC, Bates DM (2000) Mixed-effects models in S and S-Plus. Springer Verlag, New York, NY

Pinsky ML, Jensen OP, Ricard D, Palumbi SR (2011) Unexpected patterns of fisheries collapse in the world's oceans. Proc Natl Acad Sci USA 108:8317-8322

Pope JG (1975) The application of mixed fisheries theory to the cod and redfish stocks of subarea 2 and division $3 \mathrm{~K}$. ICNAF Res Doc 75/IX/126. International Commission for the Northwest Atlantic Fisheries (ICNAF), Dartmouth, NS

Pope JG (1979) Stock assessment in multispecies fisheries, with special reference to the trawl fishery in the Gulf of Thailand. SCS/DEV/79/19. Food and Agriculture Organization (FAO), Manila

Punt AE (2003) Extending production models to include process error in the population dynamics. Can J Fish Aquat Sci 60:1217-1228

R Development Core Team (2011) R: a language and environment for statistical computing. R Foundation for Statistical Computing, Vienna. www.R-project.org/

Ralston S, Polovina JJ (1982) A multispecies analysis of the commercial deep-sea handline fishery in Hawaii. Fish Bull 80:435-448

Restrepo VR, Mace PM, Serchuk FM (1999) The precaution- ary approach: a new paradigm or business as usual? NOAA Tech Memo NMFS-F/SPO:61-70. National Marine Fisheries Service (NMFS), Silver Spring, MD

Scheffer M, Carpenter SR (2003) Catastrophic regime shifts in ecosystems: linking theory to observation. Trends Ecol Evol 18:648-656

> Schweigert JF, Boldt JL, Flostrand L, Cleary JS (2010) A review of factors limiting recovery of Pacific herring stocks in Canada. ICES J Mar Sci 67:1903-1913

Shackell NL, Frank KT, Fisher JAD, Petrie B, Leggett WC (2010) Decline in top predator body size and changing climate alter trophic structure in an oceanic ecosystem. Proc R Soc B 277:1353-1360

Shackell NL, Bundy A, Nye JA, Link JS (2012) Common large-scale responses to climate and fishing across Northwest Atlantic ecosystems. ICES J Mar Sci 69:151-162

Sherman K, Belkin IM, Friedland KD, O'Reilly J, Hyde K (2009) Accelerated warming and emergent trends in fisheries biomass yields of the world's large marine ecosystems. Ambio 38:215-224

Smith TD (1994) Scaling fisheries: the science of measuring the effects of fishing, 1855-1955. Cambridge University Press, New York, NY

> Smith TD, Link JS (2005) Autopsy your dead...and living: a proposal for fisheries science, fisheries management and fisheries. Fish Fish 6:73-87

Steele JH (2004) Regime shifts in the ocean: reconciling observations and theory. Prog Oceanogr 60:135-141

Trzcinski MK, Mohn R, Bowen WD (2009) Estimating the impact of grey seals on the Eastern Scotian Shelf and Western Scotian Shelf cod populations. DFO Can Sci Advis Sec Res Doc 2009/052. Fisheries and Oceans Canada, Ottawa

> Tyrrell MC, Link JS, Moustahfid H (2011) The importance of including predation in fish population models: implications for biological reference points. Fish Res 108:1-8

Walters CJ, Hilborn R (1976) Adaptive control of fishing systems. J Fish Res Board Can 33:145-159

Walters CJ, Christensen V, Martell SJ, Kitchell JF (2005) Possible ecosystem impacts of applying MSY policies from single-species assessment. ICES J Mar Sci 62: 558-568

- Ware DM, Thomson RE (2005) Bottom-up ecosystem trophic dynamics determine fish production in the Northeast Pacific. Science 308:1280-1284

Witherell D, Pautzke C, Fluharty D (2000) An ecosystembased approach for Alaska groundfish fisheries. ICES J Mar Sci 57:771-777

> Worm B, Hilborn R, Baum JK, Branch TA and others (2009) Rebuilding global fisheries. Science 325:578-585

Zhou S, Smith ADM, Punt AE, Richardson AJ and others (2010) Ecosystem-based fisheries management requires a change to the selective fishing philosophy. Proc Natl Acad Sci USA 107:9485-9489

Proofs received from author(s): July 3, 2012 